\title{
Presentación \\ Ideas lingüísticas y pedagógicas en la prensa de España y América del siglo XIX
}

\author{
Victoriano Gaviño Rodríguez \\ Universidad de Cádiz
}

La historiografía lingüística hispánica ha experimentado un amplio desarrollo en estas últimas décadas, especialmente desde comienzos del siglo XXI, con la incorporación de nuevos conceptos y herramientas metodológicas que a día hoy permiten un estudio más sistemático de la transtextualidad entre obras $\mathrm{y}$, de este modo, de las relaciones entre autores, ideas, corrientes, etc., lo cual redunda en una mayor precisión delimitativa de las bases canónicas sobre las que se asienta el constructo del pensamiento lingüístico elaborado desde la disciplina. En esta renovación de los estudios historiográficos juegan un papel importante el agotamiento del modelo anterior y la mejora en el acceso a las fuentes documentales que sirven de objeto de investigación en este campo, que han conducido a que muchos trabajos actuales no limiten tanto su interés al examen de obras singulares o tradicionalmente consideradas canónicas para el análisis historiográfico, sino al estudio seriado de textos (por lo general, gramáticas, ortografías o diccionarios considerados en conjunto como series textuales) pertenecientes a una misma tradición discursiva o no, cuyos contrastes de ideas aportan un indudable enriquecimiento para la investigación historiográfica. A esto conviene además sumar la importante labor que en los últimos años han desempeñado algunas investigaciones con el análisis de fuentes documentales poco exploradas en el ámbito hispánico, entre las que cabe destacar, por un lado, las publicadas por autores poco conocidos o aquellas escasamente exploradas y editadas específicamente en el continente americano y, por otro, las pertenecientes 
a otras tipologías (prensa, apuntes, borradores, correspondencia privada) que, por su desconocimiento, singularidad o menor atención, aportan nuevas perspectivas complementarias a las visiones parciales que, por lo general, se pudieran desentrañar a partir del examen de una única realidad acontecida.

La sección monográfica que da continuación a este preludio se centra precisamente en una de estas fuentes no canónicas, en este caso, la de la prensa española y americana del XIX, un medio que ya ha sido ampliamente abordado desde otros campos como la historia y la literatura, pero que apenas ha contado con parciales y leves incursiones en lo concerniente al estudio lingüístico, a pesar de la importante repercusión que para la historia de las ideas lingüísticas de la época representan las producciones textuales de diarios, periódicos y revistas. A medida que avanza el siglo, la prensa decimonónica deja de tener por destinatario a la élite (así había funcionado en la centuria anterior) y se convierte en tribuna pública al alcance de la sociedad en general; se produce una profusión de publicaciones periódicas en español, tanto en España como en las recién independizadas repúblicas hispanoamericanas, que abarcan un amplio espectro de asuntos, de entre los cuales el tema lingüístico cobra un protagonismo especial, básicamente, por la trascendencia que los distintos gobiernos otorgan a la lengua y su enseñanza como elemento esencial en el progreso de las naciones, pero también como asunto específico en relación con las necesidades de mejora de su enseñanza en la escuela, en cuyo proceso juega un papel fundamental el desarrollo de la prensa pedagógica especializada, donde los maestros cobran un particular protagonismo dando muestra de su sensibilidad y opiniones ante estos asuntos.

La prensa se convierte, en este sentido, en púlpito y tribuna abierta a todos, el escenario de apasionados debates cuando no de impetuosas confrontaciones ideológicas que también afectan al elemento lingüístico, sobre el cual se visualizan debates más o menos intensos en relación con algunos asuntos como el de la regulación ortográfica, la innovación léxica, el purismo lingüístico, la enseñanza y sus métodos, etc. Estamos ante un periodo crucial para la reflexión lingüística y la prensa es muestra de todo ello: acompañando a las tradicionales noticias y reseñas de obras lingüísticas, que nos permiten conocer más sobre la difusión de los tratados (así como el alcance o grado de aceptación que estos pudieron tener, tanto entre profesionales como en la propia sociedad), en la prensa surgen nuevos géneros discursivos en forma de artículos de opinión sobre asuntos de ortografía, gramática, léxico, etc., que ocupan un lugar central en muchas de las publicaciones especializadas del momento: abundan en las páginas las propuestas sobre teorías lingüísticas, ya sean de manera independiente o al hilo de las postuladas por determinados autores u obras, así como 
debates, polémicas lingüísticas o un sinfín de aspectos que en un medio como este se muestran en constante vinculación con procesos históricos de decisión política o educativa claves para la contextualización de algunos acontecimientos y la delimitación de las tendencias ideológicas que sirven para la reconstrucción del hilo diacrónico de los sucesivos cambios que se producen a lo largo de la historia.

En un aspecto como el de la lengua, que con frecuencia da el salto desde el ámbito especializado al coloquio social, hay que tener también en cuenta el papel fundamental que en el siglo XIX desempeña la prensa como espacio de opinión pública y cauce de las opiniones sociales, la exposición de ideologías lingüísticas, creencias y actitudes ante la lengua. Los periódicos pasan a convertirse en una herramienta social para la defensa pública de muy diversas ideas en relación con intereses particulares de grupos concretos, pero también con los perseguidos por sus miembros de manera individual, convirtiendo algunas intervenciones en un trampolín para la proyección social o la consecución de un determinado objetivo (en ocasiones, el interés económico que se persigue con la venta de libros, la publicidad de clases privadas, etc.). Es en este punto en el que surge el debate argumentado de ideas, con sólidas posiciones en las que las plumas de intelectuales o especialistas martillean a sus adversarios y sirven de defensa ideológica de las distintas posiciones que ahora se enfrentan en la búsqueda de una victoria o la denuncia en conflicto con el poder, encarnado generalmente por la Real Academia Española y su papel privilegiado como órgano regulador de la norma lingüística del español.

Hasta la actualidad, apenas se han llevado incursiones sistemáticas de las publicaciones periodísticas que durante este periodo dan muestra de las ideologías y tendencias que se desarrollan en relación con la lengua y su enseñanza, de modo que esta sección intentará profundizar en algunos de estos aspectos, no sin proclamar que para ello nos subimos en los hombros de aquellas investigaciones que ya nos han precedido con importantes incursiones, a partir de las cuales partimos para dar difusión a algunos de los avances desarrollados en el marco del proyecto nacional de investigación "LinPePrensa. Ideas lingüísticas y pedagógicas en la prensa española del siglo XIX” (Mineco, Gobierno de España, ref. PGC2018-098509-B-I00) y el autonómico, específico sobre identidad andaluza, "Actitudes lingüísticas e ideas pedagógicas en la prensa española del siglo XIX. Perspectivas sobre la identidad andaluza" (Plan andaluz de investigación, desarrollo e innovación, Junta de Andalucía, ref.: P18-RT-3117), en los cuales se enmarcan los trabajos aquí presentados. En este sentido, estas investigaciones sirven para descubrir o rescatar la producción textual de aquellos autores que han pasado desapercibidos para la historiografía lingüística hispánica y 
que ahora ponemos en valor como textos complementarios para el estudio del pensamiento lingüístico de la época, así como la de aquellos otros más conocidos por la historiografía lingüística que dejaron tras de sí la publicación de su obra no solo en formato de libros, sino también de manera dispersa en periódicos o arrumbada en cajones de escritorio. Las figuras de estos hombres no podían quedar muertas en las salas de autopsias de los eruditos; era preciso resucitarlas para el público, académico o no, que juzgará o no la valía de estas páginas desempolvadas o de esos papeles nuevos con sus ideas, sus debates, polémicas y un sinfín de informaciones acerca de sus frecuentemente olvidadas biografías. 